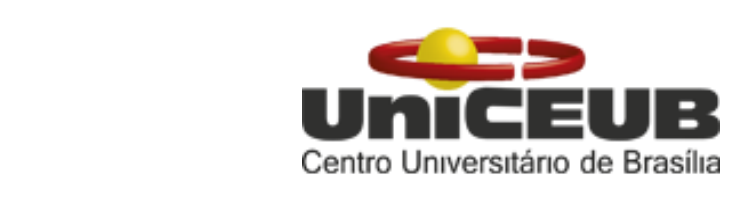

CENTRO UNIVERSITÁRIO DE BRASÍLIA - UNICEUB

PROGRAMA DE INICIAÇÃO CIENTÍFICA

MELINA GOMES BORGES

O PAPEL DE BACTÉRIAS QUERATINOLÍTICAS NA EXPRESSÃO DE CARACTERÍSTICAS ESTRUTURAIS DA PLUMAGEM DO TIZIU (Volatinia jacarina)

Brasília-DF 


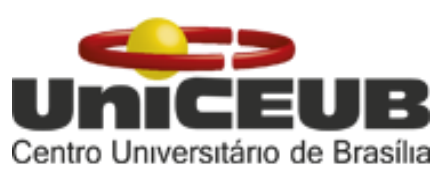

MELINA GOMES BORGES

\section{O PAPEL DE BACTÉRIAS QUERATINOLÍTICAS NA EXPRESSÃO DE CARACTERÍSTICAS ESTRUTURAIS DA PLUMAGEM DO TIZIU (Volatinia jacarina)}

Relatório final de pesquisa de Iniciação Científica apresentado à Assessoria de Pós-Graduação e Pesquisa

Orientador: Prof. Dr. Raphael Igor Dias

\section{Brasília-DF}




\section{Agradecimento}

Agradeço a todos que contribuíram para que eu chegasse ao fim deste projeto de iniciação científica.

Ao meu orientador, professor Raphael Igor Dias, por ter me proporcionado esta experiência incrível de estar perto da ciência e aprender constantemente como executá-la da melhor forma, a mais correta. Obrigada pela paciência e cobrança para que tudo desse certo, e que me inspira desde as aulas de ecologia, com sua dedicação, zelo e compromisso em tudo o que faz, carregarei enorme admiração.

Aos meus familiares, que souberam da importância e me apoiaram para que eu fosse persistente em obter meus resultados.

Aos meus colegas de curso que contribuíram com ajudas em campo, laboratório e conversas para me distrair.

À equipe do LABOCIEN, em especial o Lula, Douglas, Karine e Érika, que sempre estiveram dispostos a me ajudar e solucionar os vários problemas que encontrei pelo caminho.

À equipe da Assessoria de pós graduação e pesquisa, professora Fernanda, Clara, Karine, Rafaella e Olívia, que sempre estiveram prontas para me auxiliar em todas as questões duvidosas que surgiram no decorrer da pesquisa, sempre muito acessíveis e dispostas!

Ao Centro Universitário de Brasília-UniCEUB pelo incentivo e estrutura fornecida para que eu realizasse as análises laboratoriais, e ao CNPq pelo fomento através da bolsa e incentivo dado aos estudantes.

Ao universo, a Deus, que me direcionou pelos melhores caminhos, que permitiu a concretização dos meus objetivos, me iluminou me deu sabedoria. 


\section{Sumário}

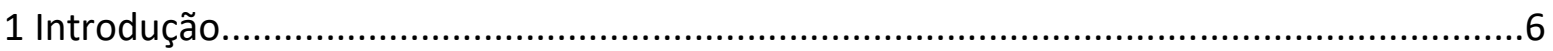

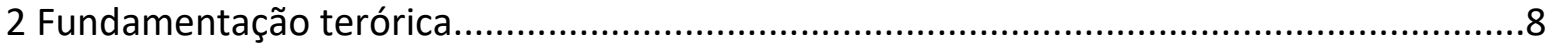

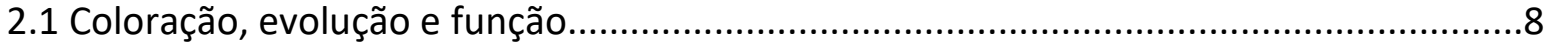

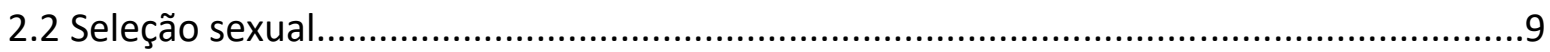

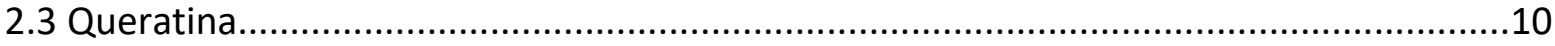

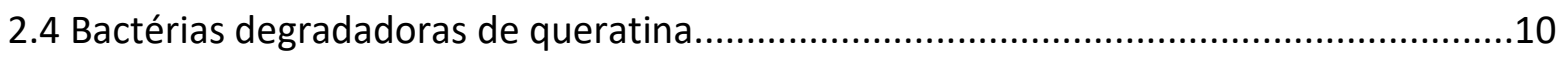

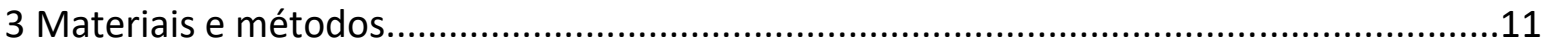

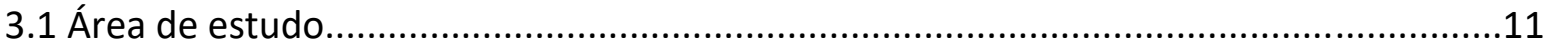

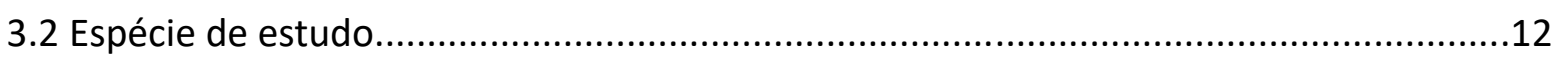

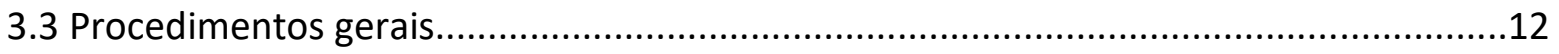

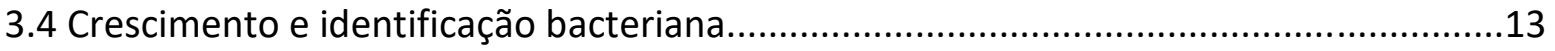

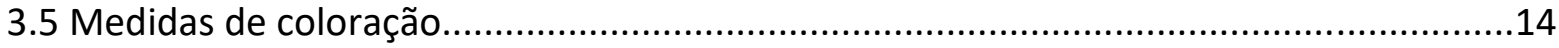

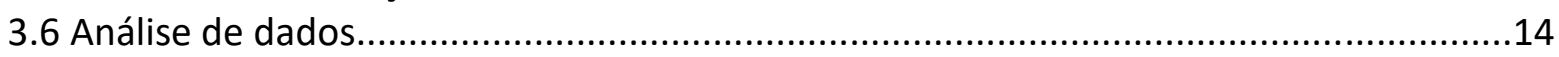

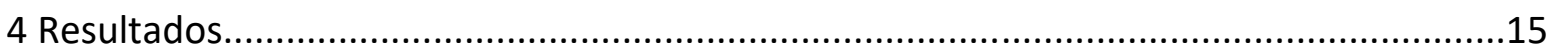

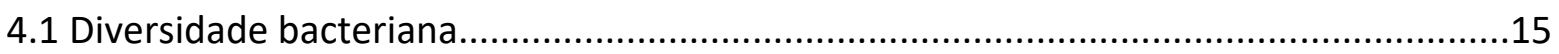

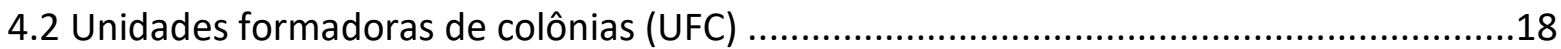

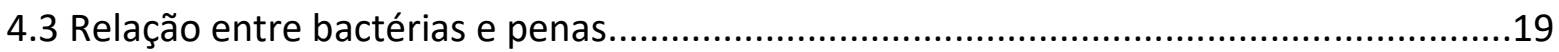

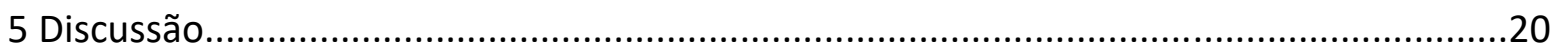

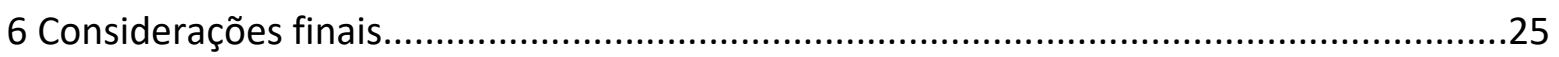

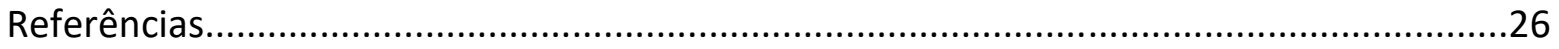




\section{RESUMO}

A comunicação entre os animais é bastante variável, havendo inúmeros mecanismos, como sinalizações sonoras, visuais, mecânicas e químicas. Nas aves, displays, cantos e combinações de cores são as formas mais comuns. A coloração pode ser produzida por meio de pigmentos ou através da organização estrutural de queratinas e melaninas nas penas, estando propenso à deterioração devido à abrasão ou danos induzidos por organismos degradantes, e esta é uma característica normalmente avaliada durante a seleção de parceiros e usualmente determina as chances reprodutivas, por sinalizar qualidade individual. Porém, os processos que regulam a produção de colorações estruturais ainda são pouco conhecidos. A Estação Ecológica de Águas Emendadas (ESECAE) está localizada na região administrativa de Planaltina, $46 \mathrm{~km}$ da região central de Brasília, e está inserida no bioma Cerrado. 0 tiziu (Volatinia jacarina) é uma espécie migratória, dicromática, granívora, cujos machos apresentam uma plumagem nupcial preto-azulada iridescente durante seu período reprodutivo. Nesse contexto, os objetivos do estudo foram: analisar possíveis diferenças na abundância de bactérias queratinolíticas presentes nas penas de machos e fêmeas de tiziu e investigar como a abundância dessas bactérias influencia a coloração. Após capturados com rede de neblina, foram coletadas, com swab, amostras bacterianas da cabeça e dorso dos indivíduos. As amostras foram armazenadas em PBS e inoculadas nos meios TSA e FMA para crescimento e posteriormente quantificação de UFCs. Adicionalmente, foram coletadas penas de contorno da cabeça e dorso para análise de coloração em espectrofotometria de luz. As variáveis colorimétricas (brilho, saturação total, saturação UV e matiz) foram reduzidas a partir de PCAs e os escores utilizados nas análises. Apesar das elevadas quantidade de UFCS em ambos os meios e da variedade, não houve efeito significativo no que diz respeito às relações entre bactérias e coloração, para o meio TSA, assim como, para o meio FMA, tanto para os machos quanto para as fêmeas. Assim como, não houve nas variáveis colorimétricas. Com relação a abundância de bactérias, foram encontradas diferenças morfológicas de vários tipos além de detectar a maior presença de bactérias gram-positivas. A diferença no número de bactérias queratinolíticas pode estar relacionada à organização estrutural de melaninas e queratinas das penas, ou ainda, a composição da microbiota pode ser mais importante do que a abundância total no processo de degradação estrutural das penas.

Palavras-chave: Coloração. Degradação de queratina. Seleção sexual. 


\section{Introdução}

Compreender como os animais se comunicam e quais os processos estão envolvidos, são assuntos bastantes complexos e que tem sido uma temática bastante estudada. Busca-se uma melhor interpretação tanto das regras envolvidas na organização das sociedades animais, quanto das bases evolutivas responsáveis pela estruturação dos sistemas de comunicação vocal (FREEBERG et al., 2012; FITCH, 2010). Há inúmeras formas de comunicação acústica no reino animal, cetáceos, por exemplo, emitem sons contínuos com frequências de $200 \mathrm{~Hz}$ e $1 \mathrm{KHz}$ que podem ser captados há quilômetros de distância. Em outros grupos, pode haver especializações para a emissão de sons como nas aves, através da siringe, ou através das pregas vocais nos mamíferos, além de comunicações por ultrassom como nos quirópteros (acima de $20.000 \mathrm{~Hz}$ ), ou seja, o que difere os sons entre as espécies são a frequência e amplitude (ELEMANS et al., 2015; BRIEFER, 2012). Há também comunicação química, que acontece através da liberação de substâncias como feromônios, como observado nas abelhas (KLEIN et al., 2010).

Nas aves, a presença de penas modificadas e coloridas geralmente são resultado de um aumento na competição e maior especificidade nos critérios de escolha dos parceiros (ANDERSSON, 2006). Sabe-se que os traços sexuais secundários, como a ornamentação da plumagem, refletem o estado de saúde dos indivíduos, por exemplo, alguns rivais podem saber do estado de saúde, status de dominância, capacidade de combate, simplesmente visualizando a coloração da plumagem (GREENE, 2000). Por outro lado, as fêmeas podem escolher parceiros para acasalamento com base em uma coloração mais saturada ou brilhante, logo, a evolução dessas características complexas deve-se a atuação da seleção sexual (HILL, 1990).

A coloração da plumagem das aves pode ser derivada da presença de pigmentos como carotenóides, melaninas, porfirinas ou da organização da camadas de queratina e melanina, responsáveis pelas chamadas colorações estruturais. Em relação à coloração baseada em pigmentos, melaninas e carotenóides são os pigmentos mais comumente encontrados em aves. Os carotenóides, por exemplo, são responsáveis pela maior parte da coloração amarela, laranja e vermelha (BRUSH, 1990). Por outro lado, colorações baseadas em melanina produzem as tonalidades pretas e marrons nas penas (MCGRAW 2006). A principal diferença entre os dois pigmentos é que carotenoides não podem ser sintetizados metabolicamente, 
sendo obtidos exclusivamente por meio da dieta (HILL, 1992). Além disso, os carotenóides podem ter efeitos fisiológicos, funções como antioxidantes ou imunoestimuladores (LOZANO, 1994).

A melanina, por sua vez, pode ser sintetizada metabolicamente, com isso, o uso potencial de colorações baseadas em melanina como um sinal honesto da qualidade individual é um pouco menos evidente. No entanto, evidências recentes sugerem que, em algumas espécies, a sinalização por melanina pode indicar variações em condições reprodutivas ou mesmo nos níveis de estresse oxidativo (GRUNST, 2014).

Há alguns anos foi descoberto que certas bactérias podem degradar as penas de aves e influenciar a expressão das características dessas penas (CLAYTON 1999). Essas bactérias pertencem a um grupo polifilético de microorganismos que são conhecidos por sua capacidade de hidrolisar a queratina. No entanto, ainda existem poucas evidências in vivo de como elas podTem influenciar a condição da plumagem das aves (CRISTOL, 2005). A queratina é uma molécula que tem funções estruturais e faz parte da constituição dos bicos, penas e algumas estruturas epidérmicas das aves. A presença dessa molécula foi vital nos processos de adaptação dos animais à diferentes ambientes naturais, pois atuam como barreiras mecânicas, estruturais e térmicas (BUSSON, 1999). Essa macromolécula é composta por uma cadeia de polipeptídio e são diversificadas em sua estrutura molecular. As variações das queratinas têm sido bastantes estudadas, no entanto, há uma baixa similaridade das sequências e uma grande diferença entre as moléculas que são encontradas. Enquanto a alfa queratina é encontrada em todos os vertebrados, a beta queratina é encontrada exclusivamente em répteis e aves. A alfa queratina é formada por uma hélice onde a estrutura peptídica se enrola em torno dela, essa estrutura confere força e elasticidade à pena, visto que a alfa queratina é ligada por pontes de dissulfeto, além de possuírem alta concentração de aminoácidos hidrofóbicos, tornando a estrutura insolúvel em água. A beta queratina, por outro lado, possui uma estrutura polipeptídica quase toda estendida, conhecida como folha beta (BRUSH, 1996).

As penas são os materiais queratinosos mais abundantes encontrados na natureza e compõem a parte estrutural das aves. Estudos anteriores demonstraram que ações de determinadas bactérias degradam e modificam a estrutura das penas, o que altera a resistência da queratina, facilitando a ação dos animais consumidores e, consequentemente, aumentando a digestibilidade das penas (ONIFADE, 1998). 
A espécie Volatinia jacarina, comumente conhecida como tiziu, é uma espécie migratória, que se desloca para regiões no centro do Brasil para reproduzir. Esta ave apresenta dicromatismo sexual, ou seja, os machos possuem uma plumagem preto-azulada brilhante que tem um componente estrutural, já as fêmeas apresentam uma cor marrom-oliva na parte superior e amarelo-amarronzado na inferior. Compreender a relação entre a presença de bactérias capazes de degradar queratina e a coloração da plumagem de indivíduos de tiziu, Volatinia jacarina.

\section{Fundamentação teórica}

\subsection{Coloração, evolução e função}

As aves formam um grupo extremamente diverso onde várias espécies apresentam ornamentos elaborados, como arranjos, plumas ou enfeites coloridos. A presença dessas estruturas reflete os efeitos da competição entre indivíduos e principalmente da escolha de parceiros (GREENE, 2000). A evolução da coloração é reflexo de pressões naturalmente ou sexualmente selecionadas. Colorações que evoluíram por meio de seleção sexual usualmente carregam informações sobre a saúde, o status de dominância ou a capacidade de combate dos indivíduos que carregam o sinal (ARNOLD, 2002). A coloração das penas é derivada principalmente pela presença de pigmentos, os mais comuns sendo carotenóides e melaninas., que são considerados sinalizadores da qualidade das plumagens (HILL, 2002). No caso dos pigmentos, a cor das penas é produzida devido a interação da luz com o respectivo pigmento. No caso de carotenoides, que produzem cores que variam do amarelo ao vermelho, todas as demais cores são absorvidas, refletindo apenas as colorações amarelo-avermelhadas. As melaninas são responsáveis por gerar colorações que vão do marrom ao negro. Penas brancas indicam a ausência de melanina e penas negras sugerem a presença em demasia do pigmento (STAVENGA et al, 2011).

No entanto, as cores também podem ser formadas pelas propriedades estruturais das penas, nelas existem estruturas semelhantes a prismas que fazem a reflexão da luz, gerando cores brilhantes e iridescentes. A ocorrência de despigmentação das cores em penas pode prejudicar os indivíduos em interações competitivas intraespecíficas, assim como, pode reduzir o potencial de sinalização da plumagem durante apresentações sexuais (DOUCET, et al, 2007). As bactérias degradadoras de penas são conhecidas por sua capacidade de hidrolisar 
a beta-queratina, que compõem mais de $90 \%$ da massa de penas, desgastando o córtex de queratina exterior (SHAWKEY et al, 2003). A melanina é sintetizada pelo próprio organismo, devido a isso a determinação da saúde do indivíduo é menos evidente. Ainda não se sabe se o pigmento colabora de fato para atividades com efeito imunológico (GRUNST, 2014). Por outro lado, existem estudos que revelaram que a degradação de penas por bactérias parecem aumentar o brilho das penas azuis, permitindo que as estruturas azuis de dispersão da luz reflitam mais feixes luminosos, ou seja, o pigmento é degradado juntamente com a queratina e a estrutura presente semelhante a um prisma é deformada, conferindo um maior brilho (SHAWKEY et al. 2007).

\subsection{Seleção sexual}

A teoria da selecão sexual é definida como um mecanismo seletivo resultante da competição reprodutiva e seleção de parceiros sexuais que visa explicar a evolução de traços sexuais elaborados (DARWIN, 1871; ANDERSSON, 2006). Porém, dispor de características elaboradas é caro para seus portadores, e assim, fornecem às fêmeas indicadores confiáveis de qualidade masculina de saúde, força para defesa de territórios, aptidão para o cuidado parental (SEARCY, NOWICKI; 2005). Em aves, a plumagem é uma das características sexualmente selecionadas mais bem estudadas em animais (McGRAW, 2002), as cores brilhantes são consideradas um clássico exemplo da expressão de padrões extremos que se manifestaram através da seleção sexual (DARWIN, 1871). Estas cores brilhantes, principalmente em machos, têm sido destacadas como modelos ideais para averiguar os diferentes tipos de informação que podem ser repassados por características ornamentais (HILL; McGRAW, 2006).

Uma variedade de sinais morfológicos, comportamentais e fisiológicos de cada animal que evoluiu em contextos sociais, influenciará nas decisões daqueles que irão receber o sinal (WESTNEAT, 2012; RUXTON, SCHAEFER; 2011). A confiabilidade de sinais é dependente dos custos associados à sua produção, ostentação e/ou manutenção, e uma parte importante dos custos de manutenção está relacionada aos recursos alocados para evitar a degradação do sinal (HORROCKS et al, 2012). 
Qualquer sinal baseado na organização estrutural está sujeito à deterioração devido à abrasão ou danos induzidos por microorganismos degradantes de estruturas proteicas, como a queratina, através da producao de enzimas proteolíticas alcalinas (queratinase) que removem essas partículas; tambem pode-se incluir a digestão anaeróbia de resíduos de penas (GUPTA; RAMNANI, 2006; CORTEZI, 2009). Assim, esses sinais podem exigir custos adicionais de manutenção relacionados a defendê-los da exposição ao meio físico e biológico (RUIZRODRIGUES et al, 2015).

\subsection{Queratina}

Queratinas são proteínas insolúveis e fibrosas encontradas em animais vertebrados, apresentando como principais funções a organização estrutural e proteção. Elas estão presentes na composição de pêlos, peles, unhas, cascos, penas e escamas (BUSSON et al. 1999). A queratina é formada pelo conjunto de unidades de aminoácidos chamados de polipeptídeos, possuindo uma massa molar média de $10.000 \mathrm{~g}$ mol-1, possuem resíduos de cisteína numa proporção de 7 a $20 \%$ da quantidade total de resíduos dos aminoácidos, um componente importante presente na beta-queratina. A queratina pertence a classe de proteínas fibrosas formada por pontes dissulfeto inter ou intramolecular, proporcionando um uma característica rígida e tenaz por causa da formação tridimensional das fibras de queratina que formam uma rede. Essa substância proteica dispõe de cadeias polipeptídicas fortemente aderidas entre si num arranjo paralelo (MOORE et al, 2006). A queratina possui cadeias proteicas compactadas na forma de estruturas conhecidas como alfa hélice ou folha beta pregueada, possuem um alto nível de enovelamento e apresentam ligações inter e intracadeia, a exemplo das ligações de dissulfeto, pontes de hidrogênio e interações hidrofóbicas, concedendo resistência à degradação proteolítica, insolubilidade e estabilidade (BRANDELLI, 2010).

\subsection{Bactérias degradadoras de queratina}

Devida a conformação da queratina, alfa hélice ou folha beta pregueada, a degradação do polipeptídeo não ocorre através da ação das proteases comuns como tripsina, a pepsina e a papaína. Apesar da queratina ser muito resistente a ação proteolítica, na natureza ocorre o 
processo de decomposição por meio de microorganismos queratinolíticos, capazes de utilizar a proteína como fonte de energia, degradando-a através da produção de queratinases, ou seja, enzimas com melhor capacidade de degradar a queratina em comparação com as proteases (OLIVEIRA, 2006). A presença de microorganismos queratinolíticos na natureza é recorrente, visto que podem ser encontrados em ambientes variados, sendo esses tanto mesófilos quanto termófilos. Assim, produzir queratinase tende a ser comum, uma vez que os microorganismos sempre atuaram na ciclagem de matéria orgânica. Dentre os microorganismos, os que mais se destacam na produção de queratinases são gram-positivos. O gênero Bacillus têm maior representação, há várias descrições de espécies que possuem o potencial queratinolítico como B. licheniformis, B. subtilis, B. cereus, B. pumilis, B. pumilus, $B$. megaterium, B. pseudofirmus, B. halodurans. Os gram-negativos também possuem capacidade queratinolítica, embora estejam em menor representatividade, tendo como exemplo alguns gêneros como Aeromonas sp., Vibrio sp., Serratia spp., Paracoccus spp. Chryseobacterium spp. e Stenotrophomonas spp. (DAROIT, 2011). Bactérias, que podem digerir a queratina, modificam sinais baseados em cor, bem como características que sinalizam a capacidade imunológica dos detentores. Ao avaliar traços que sinalizam de maneira confiável a capacidade imunológica, os receptores dos sinais são capazes de escolher parceiros menos infectados, com genes que conferem resistência a patógenos, que poderão ser herdados por seus descendentes, visto que a boa condição corporal do indivíduo informada pela coloração é uma característica passada geneticamente (BURTT; ICHIDA, 1999; SHAWKEY et al., 2007).

\section{Metodologia}

\section{1 Área de estudo}

A área de estudo está inserida no bioma Cerrado, cuja vegetação é bastante diversificada, variando de formas campestres, como os campos limpos, a formações florestais densas, como os cerradões. A Estação Ecológica de Águas Emendadas (ESECAE) $\left(15^{\circ} 33^{\prime} 17.37^{\prime \prime}\right.$; $\left.47^{\circ} 35^{\prime} 51.81^{\prime \prime} \mathrm{O}\right)$ está localizada na região administrativa de Planaltina, 46km da região central de Brasília. A região apresenta um clima considerado subtropical, caracterizado por uma estação fria e seca no inverno e outro quente e úmida no verão (DANNIOLIVEIRA, 2007). Na Estação, há a predominância da vegetação do tipo campos, veredas e de 
cerrado strictu sensu, a mata de galeria está presente, porém, em menor proporção (FERREIRA, 1976; MAURY et al.,1994; SILVA JÚNIOR; FELFILI, 1996), cerrado denso e mata mesofítica, chamada de floresta estacional ou mata seca (SEDUMA, 2008). As áreas são compostas por uma por um fitofisionomia de cerrado ralo com forte influência antrópica, gramíneas exóticas, arbustos e árvores afastadas consistem o local. Fale um pouco da localização, no entorno da reserva em contato direto com a rodovia.

\subsection{Espécie de estudo}

O tiziu, Volatinia jacarina, é um passeriforme granívoro da Família Thraupidae, seu tamanho é aproximadamente de 11,5 centímetros de comprimento e pesa cerca 10 gramas. São vistos geralmente aos pares no período reprodutivo e, passado esses momentos, costumam estar reunidos em bandos, chegando a dezenas de indivíduos. É uma espécie que migra da Amazônia para o Brasil Central durante seu período reprodutivo, que ocorre de novembro a abril e durante essa estação, fazem uma demarcação pontual do território e agem isoladamente (MURRAY Jr. 1982; ALMEIDA; MACEDO, 2001).

Durante a estação reprodutiva, os machos realizam muda gerando uma plumagem negro-azulada iridescente, com manchas subaxilares brancas, e defendem seu território com forte demarcação, embora o sejam pequenos, além de agirem isoladamente (MURRAY Jr. 1982; ALMEIDA;

MACEDO, 2001). Os machos apresentam um display para demarcar o território, caracterizado por saltos verticais de um poleiro e, com o bater das asas, exibem a mancha branca subaxilar, junto com a emissão da vocalização típica da espécie (CARVALHO et al., 2007). Os machos, fora da estação reprodutiva, apresentam uma coloração parda, o que faz com que os mesmos se assemelhem às fêmeas ou a indivíduos imaturos (CARVALHO et al., 2006) (WEBBER, 1985).

Estudos passados demonstraram que a condição corporal do indivíduo está diretamente relacionada às características espectrais da plumagem negra no período da muda (DOUCET, 2002). Particularmente, a plumagem tende a expressar a qualidade individual dos machos, visto que durante a muda é associada às características de coloração (DOUCET, 2002) e à velocidade que ela ocorre, desse modo relaciona-se à carga parasitária (COSTA; MACEDO, 2005). 


\subsection{Procedimentos gerais}

Para a captura dos animais foram utilizadas de quatro a seis redes de neblina $(12 \times 2,6 \mathrm{~m})$ posicionadas em locais pré-definidos no turno matutino antes do nascer do sol, uma vez por semana. Enquanto os indivíduos ainda estavam na rede, foi coletada uma amostra bacteriana do dorso e cabeça dos indivíduos com o uso de um swab, que foi imediatamente mergulhado em aproximadamente $1 \mathrm{ml}$ de solução estéril salina (PBS), para evitar contaminação. Após a coleta, o material foi mantido em temperatura ambiente. Na sequência, foram registradas as medidas corporais e de massa dos indivíduos. Adicionalmente, foram coletadas de cinco a sete penas de contorno da cabeça, dorso superior e inferior para análise de coloração em espectrofotômetro de luz. As penas foram armazenadas em cartões de papel com identificação do indivíduo, fixadas com fita crepe e embaladas em papel alumínio e mantido em ambiente seco e fresco. Os animais foram marcados com sequências únicas de três anilhas plásticas coloridas e uma prateada com um código alfanumérico do CEMAVE e soltos posteriormente.

\subsection{Crescimento e identificação bacteriano}

Foram utilizados dois meios de cultura diferentes para obter o crescimento bacteriano, o TSA (Tryptic Soy Agar) (Difco, Detroit, MI) e o FMA (Feather Meal Agar) contendo $15 \mathrm{~g} \mathrm{~L}^{-1}$ farinha de pena, 0,5 $\mathrm{g} \mathrm{L}^{-1} \mathrm{NaCl}$ 0,30 $\mathrm{g} \mathrm{L}^{-1} \mathrm{~K} 2 \mathrm{HPO} 4,0,40 \mathrm{~g}^{-1} \mathrm{KH} 2 \mathrm{PO} 4$, e $15 \mathrm{~g} \mathrm{~L}^{-1}$ ágar (SANGALI, BRANDELLI; 2000). O TSA é um meio não seletivo, que estimula o crescimento de uma ubiquidade de microrganismos, por isso o uso dele permite a quantificação da carga total de bactérias presentes nas penas. Já o FMA, por ser um meio seletivo, foi usado para estimular obter o crescimento de bactérias cujo potencial de degradação de queratina seja evidente. Devida a presença de queratina de penas como sua única fonte de carbono, as bactérias que se desenvolvem nesse meio têm a capacidade queratinolítica. A partir da amostra em PBS, foi feito o plaqueamento de $100 \mu \mathrm{L}$ em ambos os meios usados, TSA e FMA, e incubados a $37^{\circ} \mathrm{C}$. Os períodos de crescimento são diferentes, o TSA necessita de 48h na estufa e o FMA de 14 dias, pois a fonte de nutriente para estes microrganismos são carbono e nitrogênio, devido quebra mais lenta das moléculas por bactérias queratinolíticas. Inicialmente, foi realizado o 
primeiro plaqueamento em meio TSA, a partir da amostra em PBS, após $48 \mathrm{~h}$ a $37{ }^{\circ} \mathrm{C}$ foi verificado o crescimento da estirpe e em seguida, utilizando uma alça estéril, foi inoculado em meio FMB (Feather Meal Broth) e crescido por $72 \mathrm{~h}$ a $37^{\circ} \mathrm{C}$. A partir deste inóculo, foi realizado o plaqueamento de $100 \mu \mathrm{L}$ em meio FMA e incubado por 14 dias para obter a bactéria queratinolítica (SANGALI, BRANDELLI; 2000). Para a contagem de UFC (Unidade Formadora de Colônias), foram realizadas triplicatas dos plaqueamentos, em ambos os meios de ágar. A suspensão bacteriana foi diluída até a potência de $10^{-6}$ em PBS e posteriormente semeada nas placas. Após o período de crescimentos pré-estabelecido, foi realizada a leitura das placas através da contagem das colônias. Após essa etapa, o número de unidades formadoras de colônias (UFC) em cada placa foi contado, somado e obtido uma média dos valores. Para cada tipo de meio para estimar o total das cargas bacterianas degradantes (MILES, MISRA; 1938).

As colônias bacterianas podem ser classificadas por meio de metodologias variadas, uma delas é a identificação de morfo-tipo das colônias, cada gênero tende a apresentar um aspecto morfológico que permite uma noção de qual organismo está sendo observado. Basicamente, as bactérias são classificadas por três critérios: forma, elevação e margem, além de utilizar uma identificação química, a coloração de gram (PRADHAN, 2017).

\subsection{Medidas de coloração}

As penas coletadas foram organizadas uma sobre a outra para imitar a disposição natural das penas no pássaro. A coloração das penas foi analisada com um espectrofotômetro USB4000 com uma fonte de luz de xenônio pulsada PX-2250-750 nm, para captar o comprimento de onda entre $300 \mathrm{~nm}$ e $700 \mathrm{~nm}$. A sonda foi mantida em um ângulo de $90^{\circ} \mathrm{em}$ um ambiente onde é excluída toda interferência de luz externa. A distância entre a sonda e as penas foi de $2 \mathrm{~mm}$. Foram realizadas três medidas diferentes para cada conjunto de penas das áreas amostradas da plumagem, sendo registrada a média de refletância por área por indivíduo. A partir desses espectros foi calculado a matiz (comprimento de onda de máxima refletância), o brilho (área total sob a curva de reflexão entre 300-700 nm) e o croma do comprimento ultravioleta (a proporção de refletância total entre 300-400 nm) (HART; HUNT, 2007).

\subsection{Análise de dados}


Ao analisar a coloração da plumagem iridescente preto-azulada uma análise de componentes principais foram utilizadas para ordenar as seguintes variáveis: brilho, matiz, saturação e saturação de UV, objetivando a redução do número de variáveis potenciais correlacionadas. Posteriormente, as cargas dos componentes selecionados foram utilizadas como variáveis resposta em modelos lineares gerais. Os dois primeiros eixos gerados (PC1 e PC2) explicaram $60 \%$ da variação dos dados. O primeiro componente principal (PC1) está correlacionado negativamente com brilho, saturação e saturação de UV, ou seja, quanto maior os valores da PC1, menos brilho nas plumagens e menos saturadas no UV, já na componente principal dois (PC2) está fortemente correlacionado ao brilho de forma positiva.

Tabela 1: Coeficientes para os três primeiros componentes de uma análise de componentes principais para seis variáveis relativas às características do espectro de reflexão de penas do manto de machos de tiziu.

\begin{tabular}{lcccc}
\hline Variável & PC1 & PC2 & PC3 & PC4 \\
\hline Brilho & -0.10 & 0,99 & -0.04 & -0.05 \\
Saturação & -0.60 & -0.013 & 0.22 & 0.76 \\
Matiz & 0.57 & 0.065 & -0.53 & 0.61 \\
Saturação de UV & -0.53 & -0.10 & 0.81 & 0.61 \\
Variância explicativa (\%) & 0.60 & 0.85 & 0.95 & 1.00 \\
\hline
\end{tabular}

Foi realizado um modelo linear generalizado, para avaliar a existência na diferença do número de bactérias e a condição corporal do indivíduo. O sexo dos indivíduos, a riqueza de espécies queratinolíticas e a abundância de colônias identificadas nos meios foram utilizados como variáveis explicativas. Todas as análises foram realizadas no programa $\mathrm{R}$ por meio do pacote PAVO (MAIA, 2016).

\section{Resultados}

\subsection{Diversidade bacteriana}

A predominância nas amostras foi de apenas um perfil morfológico crescida nos meios, em alguns casos ocorreu o crescimento de duas ou três variedades, porém só foi identificado este crescimento diversificado no meio TSA. 
Foram analisadas 176 amostras, ou seja, 176 indivíduos foram capturados e para cada indivíduo foi usado somente um swab, sendo 109 fêmeas e 67 machos. Em TSA, houve o crescimento de 123 amostras e em FMA 53 amostras, a diferença entre a quantidade em ambos os meios de cultura foi devida a especificidade do meio FMA, devido a este fator não houve o crescimento de todas as amostras. Todas as amostras tiveram registros de aspecto morfológico e químico (Tabela 1). Foi encontrado uma alta taxa de bactérias gram-positivas sendo mais da metade $(55,68 \%)$ possuindo esta característica química e pouco menos da metade $(44,31 \%)$ sendo gram-negativa.

Tabela 2 - aspectos morfológicos e químicos das bactérias em TSA e FMA.

\begin{tabular}{|c|c|c|}
\hline \multirow[b]{2}{*}{ Característica analisada } & \multicolumn{2}{|c|}{ Quantidade } \\
\hline & Meio de cultura TSA & Meio de cultura FMA \\
\hline \multicolumn{3}{|l|}{ Pigmento } \\
\hline Amarelado & 41 & 13 \\
\hline Amarronzado & 50 & 8 \\
\hline Branco & 29 & 30 \\
\hline Laranja & 3 & 2 \\
\hline \multicolumn{3}{|l|}{ Forma } \\
\hline Circular & 123 & 53 \\
\hline \multicolumn{3}{|l|}{ Elevação } \\
\hline Elevada & 55 & 0 \\
\hline Achatada & 62 & 53 \\
\hline Convexa & 6 & 0 \\
\hline \multicolumn{3}{|l|}{ Margem } \\
\hline Regular & 123 & 53 \\
\hline \multicolumn{3}{|l|}{ Densidade } \\
\hline Opaca & 67 & 53 \\
\hline Translucida & 56 & 0 \\
\hline \multicolumn{3}{|l|}{ Consistência } \\
\hline Amanteigada & 50 & 6 \\
\hline
\end{tabular}


Pegajosa

Mucoide

Seca

Superfície

Brilhante

Cremosa

Embaçada

\section{Coloração gram}

Coco; gram +

Coco; gram -

Bacilo; gram +

Bacilo gram -
16

0

57

3

44

52

1

4

67

52

67

38

9

4

31

4

16 
Embora tenha ocorrido o crescimento de uma variedade bacteriana nos meios de cultura, não foi possível determinar nada relacionado ao gênero e espécie, visto que as informações obtidas de parâmetros morfológicos e químicos não são suficientes, e análise molecular esteve fora do alcance durante a realização da pesquisa.

\subsection{Unidades Formadoras de Colônias (UFC)}

As unidades formadoras de colônias foram obtidas no prazo de $48 \mathrm{~h}$ para o meio TSA e 14 dias para o meio FMA. As colônias crescidas em TSA apresentaram instabilidade com relação a concentração que havia no PBS e no pré-inóculo feito em TSB. Essa divergência não possibilitou que todas as diluições fossem as mesmas, cujo objetivo era padronizar na potência $10^{-6}$. As UFCs foram então contabilizadas nas potências $10^{-4}, 10^{-5}$ e $10^{-6}$. As UFCs do FMA também foram contabilizadas entre as potências $10^{-4}, 10^{-5}$ e $10^{-6}$. Apesar disso, só foram utilizados os valores obtidos em $10^{-6}$ nos dois meios de cultura. Para o meio TSA ocorreu uma variação de $2 \times 10^{-6}$ a $280 \times 10^{-6}$ demonstrando assim a grande inconstante na quantidade de bactérias presentes no inóculo além de mostrar que há uma grande quantidade de bactérias generalistas (Fig. 1), já para o FMA $12 \times 10^{-6}$ a $64 \times 10^{-6}$ o que também confirma a oscilação entre as diluições, porém, o resultado apresenta uma menor quantidade de bactérias nesse meio seletivo em relação ao meio não seletivo, o que era esperado para se encontrar (Fig. 2).

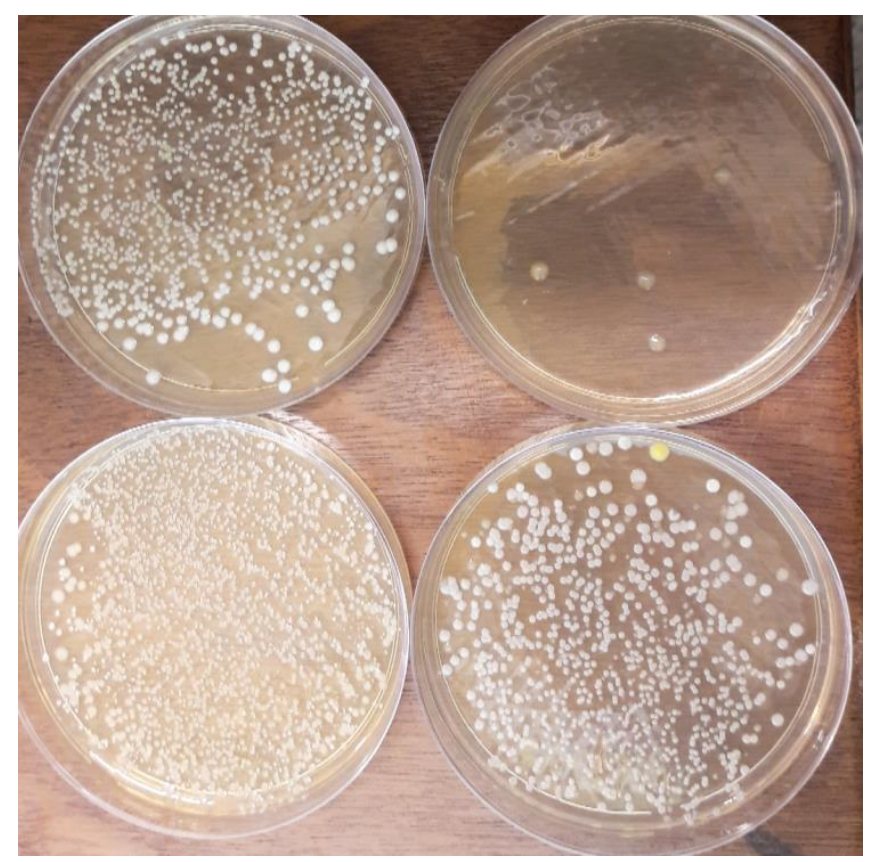

Figura 1: UFC crescidas em TSA (quatro indivíduos diferentes). 


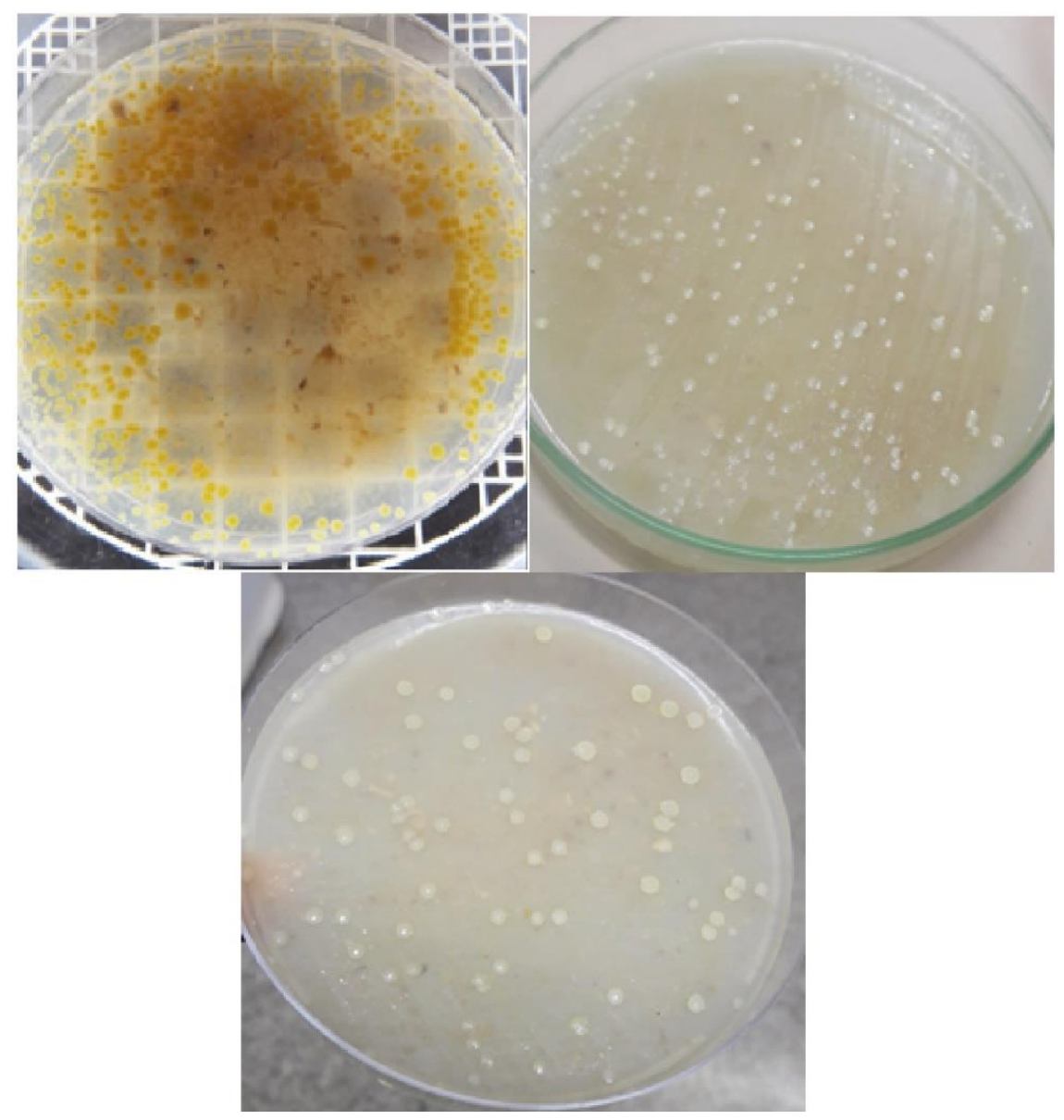

Figura 2: UFC crescidas em FMA (três indivíduos diferentes).

\subsection{Relações entre bactérias e coloração}

Das 176 amostras de penas negro azuladas e swabs, 109 são pertencentes às fêmeas e 67 aos machos. As questões de diferença na quantidade de UFC em ambos os meios, foram analisadas e nos dois sexos em meio TSA não houve uma diferença significativa nos valores obtidos de UFC, assim como para os meios FMA tanto para os machos quanto para as fêmeas o resultado não demonstrou significância para o crescimento de bactérias UFC - TSA (GLM; $t$ $=-0,170 ; p=0,866)$, e UFC-FMA (GLM; $t=1,518 ; p=0,134)$. Os valores totais obtidos das UFCs

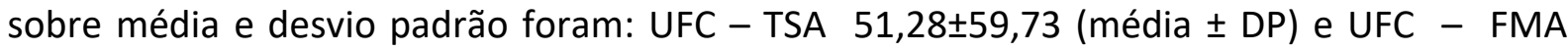
$14,12 \pm 19,11$ (média \pm DP); entre fêmeas e machos os valores foram: UFC - TSA 55, $30 \pm 19,86$

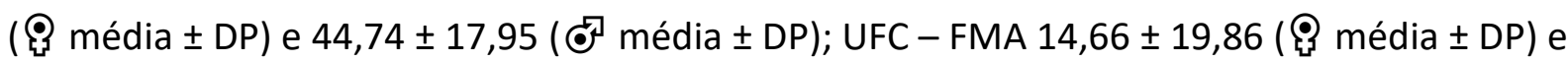
$19,86 \pm 17,95$ ( क média \pm DP) . 
Além disso, do total de amostras, os valores obtidos para as PCAs investigadas foram utilizados para explicar se existe algum efeito das bactérias na cor dos machos. O primeiro componente está carregado positivamente pela matiz e negativamente pela saturação e saturação UV. Dessa forma, as cargas usadas nas análises representam variações individuais nessa escala do componente, ou seja, valores altos das cargas do PC1 representam indivíduos com valores altos para matiz, mas baixos para saturação e saturação UV e o segundo componente (PC2) está fortemente correlacionado ao brilho de forma negativa, por isso este componente não foi considerado por ter apenas um parâmetro respondendo, logo, somente o valor do brilho foi usado.

Foram encontrados os valores totais de brilho de 6,52 $\pm 1,52$ (média $\pm D P$ ); de saturação 0,19 \pm 0,04 (média \pm DP); de saturação de UV 0,04 \pm 0,24 (média \pm DP); e de matiz 650,653 \pm 88,49 (média \pm DP). Entre machos e fêmeas os valores obtidos foram brilho $6,09 \pm 1,08$ (

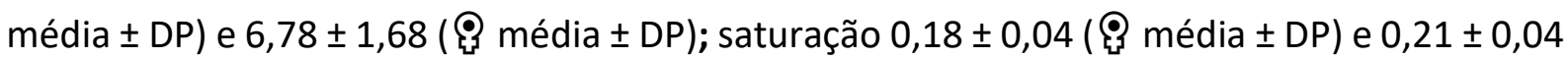

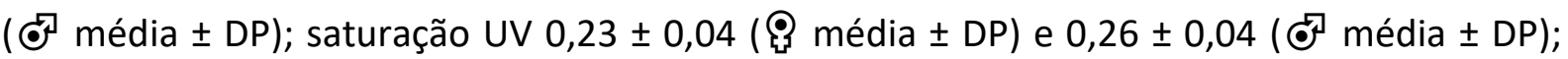
matiz 693,11 \pm 35,77 ( $\&$ média \pm DP) e 581,56 \pm 104,15 ( f média \pm DP).

\section{Discussão}

As análises iniciais das quatro variáveis demonstraram que as relações entre as bactérias e a coloração não tiveram efeito significativo $(p<0,05)$. Dentro das variáveis colorimétricas, o resultado encontrado de PC1 e PC2 demonstrou a não significância, com isso, não é possível determinar os efeitos, sejam eles negativos ou positivos na condição corporal do tiziu, em ambos os sexos.

Estudos passados demonstraram que a condição corporal do indivíduo está diretamente relacionada às características espectrais da plumagem negra no período da muda (DOUCET, 2002). Particularmente, a plumagem tende a expressar a qualidade individual dos machos, visto que durante a muda é associada às características de coloração (DOUCET, 2002) e à velocidade que ela ocorre, desse modo relaciona-se à carga parasitária, uma vez que a qualidade individual está atrelada a vivacidade da cor (COSTA; MACEDO, 2005).

Outros autores, encontraram efeitos significativos em que nos machos uma cor estrutural mais brilhante estaria ligada a maior abundância de UFCs. A explicação dada para 
isso, carga bacteriana e cor, pode ter surgido de várias maneiras, por exemplo, através da defesa de territórios, seguidos de comportamentos de cuidados de saneamento individual. (SHAWKEY, 2007).

Ainda assim, embora o resultado não indique relação entre a carga bacteriana e a cor, autores como POIANI et al. (2000), sugerem que a dominância dos machos pode acarretar custos de saúde. Similarmente, Sturnus vulgaris com cargas de trabalho reprodutivas aumentadas experimentalmente tinham numerosas associações bacterianas em suas penas do que os indivíduos com cargas de trabalho reduzidas (LUCAS et al. 2005), talvez porque eles dedicaram menos tempo para o comportamento de saneamento. Pássaros negro azulados mais brilhantes também podem criar um número maior de aves jovens do que os mais "apagados" e, assim, investir mais energia na reprodução, deixando menos para automanutenção (SIEFFERMAN; HILL, 2003).

No entanto, talvez não seja tão certeiro saber se as bactérias teriam tais efeitos, algumas dessas bactérias podem ser benéficas (LOMBARDO et al., 1999), e as aves mais brilhantes podem ter mais capacidades de adquirir ou aumentar o crescimento dessas bactérias do que as aves menos brilhantes. Em particular, algumas bactérias podem excluir competitivamente o crescimento de bactérias patogênicas, como a microbiota da pele humana (TANNOCK, 1995). Para que tal resultado possa ser encontrado, este trabalho teria que ir além, com demonstrações de efeitos entre as possibilidades de associados bióticas existentes no organismo e nas penas dos indivíduos, assim, seria viável detectar se as bactérias queratinolíticas teriam uma atividade solitária ou se de fato haveria um trabalho conjunto destas interações da microbiota.

Contrapondo, as bactérias podem alterar diretamente a cor da plumagem (SHAWKEY; HILL, 2004). Se os machos mais brilhantes têm mais bactérias, porque as bactérias afetam as penas de uma forma que aumenta o brilho, espera-se ver uma correlação mais forte entre a abundância de UFC queratinolítica e a cor do que entre a abundância total de UFC e a cor (SHAWKEY, 2007).

Embora os valores não significativos obtidos através das análises não demonstrarem efeitos, outro resultado interessante que foi descrito neste trabalho é a questão da morfologia microscópica das colônias bacterianas. Tais aspectos, relacionados a coloração gram, podem auxiliar na compreensão do porquê não houve efeito na condição corpórea e na coloração. 
Foram identificadas no meio TSA 98 estirpes com característica gram positiva (31 bacilos e 67 cocos) e 25 gram negativas (16 bacilos e 8 cocos) em meio FMA 42 gram positivas (4 cocos e 7 bacilos) e 25 gram negativos (4 cocos e 7 bacilos). Shawkey, Pillai e Hill (2008) isolaram 22 táxons de bactéria, dois destes táxons crescidos em FMA possuíam característica gram-negativos (Pseudomonas pseudoalcaligenes, Pseudomonas putida) e o restante foi gram-positivo. Dos gêneros isolados, a atividade queratinolítica foi relatada anteriormente em Bacillus (EL-SHORA et al., 1993; BURTT; ICHIDA, 1999; SHAWKEY et al., 2003), Streptomyces (NOVAL; NICKERSON, 1959; BOCKLE et al., 1995; ICHIDA et al., 2001), Arthrobacter (LUCAS et al., 2003) e Pseudomonas (LUCAS et al., 2003; SHAWKEY et al., 2003). Porém, Daroit (2011) afirma que bactérias com essa propriedade queratinolítica está relacionada as gram positivas, sendo o gênero Bacillus com maior representação, além de ter relatos de espécies que possuem o potencial queratinolítico como B. licheniformis, B. subtilis, B. cereus, B. pumilis, B. pumilus, B. megaterium, B. pseudofirmus, B. halodurans, ele diz que os gêneros como Aeromonas sp., Vibrio sp., Serratia spp., Paracoccus spp. Chryseobacterium spp. e Stenotrophomonas spp., classificados como gram negativos tem o potencial porém são a minoria. Isto corrobora com os resultados deste trabalho serem similares ao citado anteriormente, com relação a quantidade de gram positivo e negativo, ainda assim não é possível auferir a relação do tipo de bactéria que estava presente, visto que, seria necessário a identificação bioquímica e/ou molecular de cada estirpe crescida para verificar se estariam enquadradas dentro de alguns destes táxons já descritos como queratinolíticos.

A coloração estrutural azul, no entanto, é criada por mecanismos inteiramente diferentes do que a coloração baseada em pigmentos (PRUM et al., 1999; SHAWKEY et al., 2003), e a evolução da coloração estrutural azul é provavelmente impulsionada por diferentes pressões; por exemplo, há pouca evidência de que as fêmeas escolher parceiros com base na coloração estrutural (BALLENTINE; HILL, 2003; LIU et al., 2006), embora possa ser usado em machos - competição masculina (SIEFFERMAN; HILL, 2005).

Outros estudos mostraram correlações entre a plumagem cor e abundância de parasitas (HILL,2006). Bactérias degradadoras de penas podem afetar diretamente a cor do pássaro, destruindo farpas coloridas entre a muda e a época de reprodução. Bactérias degradadoras de penas parecem aumentar o brilho das penas azuis estruturais, desgastando o córtex externo de queratina, permitindo que as estruturas azuis de dispersão de luz reflitam mais luz (SHAWKEY et al., 2007). 
Este fator então, demonstra que a não relação entre as cargas bacterianas e as cores encontrada deve-se, possivelmente ao fato de que conjuntos inteiros de microrganismos podem ser necessários para a quebra de penas na natureza. Além disso, certas bactérias queratinolíticas podem ser mais efetivas na quebra de penas do que outras, mas podem não ser numericamente dominantes. A relação entre essas importantes bactérias queratinolíticas e a cor da plumagem pode ter sido afetada nas análises.

Ainda assim, as relações entre estes fatores são importantes para compreender aspectos de interação, sejam eles de competição ou acasalamento. Lynn e Cole (2019) testaram outros efeitos nos parâmetros da cor e as preferências femininas, como contraste na matiz, saturação e brilho, que tiveram efeitos significativo e foi determinado o efeito, em que as fêmeas detectavam a variação e, faz com que cada uma das medidas de contraste seja uma potencial escolha de acasalamento. Os sinais de cores complexos, altamente polimórficos, estão ligados a seleção sexual, neste trabalho por não ter tido efeito não foi possível determinar níveis de sinais possíveis nas interações entre os sexo, mas de acordo com Trigali e Bowman (2012), a saturação UV mais elevada em macho do que em fêmeas demonstra mais dominância e, entre os juvenis, os machos foram mais propensos a serem dominantes e têm maior cintilância UV do que as fêmeas, sugerindo que saturação UV pode sinalizar sexo, que está associado à dominância. Porém, há trabalhos mostrando que a plumagem pode sinalizar agressividade ou vontade de lutar (SMITH; HARPER, 1988; VEDDER et al., 2010), em vez do verdadeiro domínio. Em nossa espécie de estudo, a agressividade e a dominância estão relacionadas, de modo que as aves dominantes são mais propensas a iniciar interações agressivas e ganhá-los, por isso não há necessidade de uma distinção entre agressividade e dominância. Ornamentos múltiplos podem transmitir mensagens diferentes, ser redundantes ou variar em confiabilidade (MOLLER; POMIANKOWSKI, 1993), e os diferentes componentes da cor da plumagem podem ser relacionados a diferentes características (SILVA et al., 2008). Por isso, o não efeito significativo encontrado não permite apresentar as formas dessas transmissões de sinais ou ainda se há diferença na forma que é passada, pois, machos apresentam a iridescência com mais evidencia e as fêmeas não possuem este artifício.

$\mathrm{Na}$ literatura há relatado que os animais podem explorar essa característica da iridescência de várias maneiras. Em primeiro lugar, a direcionalidade de cores iridescentes pode permitir que os animais direcionem seus sinais nos receptores pretendidos, tais como 
companheiros ou rivais. De fato, muitas espécies parecem ter evoluído modificações ultraestruturais que aumentar a direcionalidade de sinais iridescentes, como bárbulas de penas em ângulo em aves (OSORIO; HAM, 2002).

Os tizius que habitam áreas diferentes, de cerrado e regiões amazônicas, estão sendo influenciados por fatores divergentes nestes biomas, esta diferença poderia influenciar na forma que a cor é transmitida e como poderia ser afetada. Estudos mostram que outra característica única das cores iridescentes é que, dependendo da base mecanismo e visualização da geometria, eles podem ser excepcionalmente brilhantes e saturados em um grau que normalmente não é cores baseadas em pigmentos (por exemplo, Vukusic et al. 1999; Osorio \& Ham 2002). Para produzir sinais visuais conspícuos, os animais devem usar cores que geram um alto grau de contraste contra o fundo (Endler, 1990). Como as cores iridescentes são tão brilhantes e saturadas, elas podem produzir sinais altamente visíveis que geram alta contraste visual cromático e acromático contra fundos naturais, que geralmente são mais escuros e menos saturados (por exemplo, casca, vegetação, cascalho; Endler 1980; Endler \& The'ry 1996; Endler et al. 2005). Sombrio cores iridescentes, como iridescência azul-preto, também podem produzir sinais que geram alto contraste acromático por serem mais escuros do que o fundo visual (por exemplo, DOUCET et al., 2007).

De fato, vários estudos sugerem que a coloração iridescente está associada à variação na condição, e um estudo experimental demonstrou uma conexão direta entre o estresse no desenvolvimento, a arquitetura nanoestrutural e a cor iridescente em uma borboleta (KEMP et al., 2006). Além disso, as estruturas responsáveis pela produção de cores iridescentes são muitas vezes localizados na superfície dos animais e cores podem, portanto, ser mais suscetíveis ao desgaste e rasgo do que as cores baseadas em pigmentos, como sugerido por padrões de ruptura da barbela em aves (FTZPATRICK, 1998) e danos em escala dependentes da idade em borboletas (KEMP, 2006). Essas características de cores iridescentes destacam sua adequação como indicadores de idade ou qualidade em algumas espécies. No entanto, ainda precisamos de um melhor entendimento do desenvolvimento de cores iridescentes para determinar se e como o estresse no desenvolvimento pode afetar as nanoestruturas produtoras de cores, uma vez que foi dito que a união de fatores pode estar relacionada ao desgaste da estrutura. 


\section{Considerações finais}

Os achados mostraram que não há relação entre a presença de bactérias queratinolítica e a coloração. Observamos que apesar de haver grandes quantidades de UFCS presentes em ambos os meios, esta variedade não influenciou nos valores dos parâmetros colorimétricos, matiz, saturação, brilho e saturação de UV além de não ter diferença entre os machos e as fêmeas, tanto quantidade de bactérias como no efeito sob a coloração. Ainda que os resultados não demonstrem efeitos significativos no momento nos indivíduos de Volatinia jacarina, pouco se entende este mecanismo de degradação da estrutura das penas in vivo que viabilizam a coloração estrutural, visto que há inúmeros fatores que podem alterála. Estudos futuros devem focar, principalmente, no aumento do número amostral e na análise de outros parâmetros de coloração para assim poder extrair resultados que podem trazer novas perspectivas no que tange a condição corporal e a iridescência dos tizius, assim como utilizar métodos moleculares para a identificação e investigar mais as características químicas de gram. 


\section{Referências}

ALVES, E. D. L., MENDONÇA, F.; DANNI-OLIVEIRA, I. M. Climatologia: noções básicas e climas do Brasil. São Paulo: Oficina de Texto, 2007. 206 p, v. 22, n. 3, mar. 2011. ISSN 1982-4513. Disponível em: <http://www.seer.ufu.br/index.php/sociedadenatureza/article/view/9983>. Acesso em: 28 abr. 2018.

ANDERSSON, M.; SIMMONS, L. W. Sexual selection and mate choice. Trends in Ecology \& Evolution, 21, 296-302. 2006.

ARNOLD, K. E., OWENS, I. P. F. Extra-pair paternity and egg dumping in birds: Life history, parental care and the risk of retaliation. Proceedings of the Royal Society of London, Series $B$ 269:1263-1269. 2002.

BRANDELLI, A; DAROIT, D. J; RIFFEL, A. Biochemical features of microbial queratinases and their production and applications. Applied Microbiology and Biotechnology. Berlin, v.85, n. 6, p. $1735-1750.2010$.

BRIEFER, E. F. Vocal expression of emotions in mammals: mechanisms of production and evidence. Journal of Zoology, 288(1), 1-20. 2012

BRUSH A. H. Metabolism of carotenoid pigments in birds. The FASEB Journal. 4:2969-2977. 1990.

BRUSH, A. H. On the origin of feathers. Journal of Evolutionary Biology, v. 9, p.131-142, 1996.

BURTT, E. JR.; ICHIDA J. Occurrence of feather-degrading Bacilli in the plumage of birds. Auk 116:364-372. 1999.

BUSSON, B.; ENGSTRON, P.; DOUCET, J. Existence of various structural zones in keratinous tissues revealed by X-ray microdiffraction. Journal of synchrotron radiation. 1999.

CAMEIRO, T.C T. V. Percepção das cores. Disponível em: Acesso em: 01/07/2019.

CARVALHO, C. B. V.; MACEDO, R. H.; GRAVES, J. A. Breeding strategies of a socially monogamous Neotropical passerine: extra-pair fertilizations, behavior, and morphology. The Condor, Volume 108, Issue 3, 1 August 2006, Pages 579-590, Ago. 2006.

CARVALHO, C. V. B.; MACEDO, R. H. F.; GRAVES, J. A. Reproduction of blue black grassquits in Central Brazil. Brazilian Journal of Biology. 67, 275-281. 2007.

CLAYTON, D. H. Feather-busting bacteria. The Auk. 116:302-304. 1999. 
CRISTOL, D.A.; ARMSTRONG, J.L.; WHITAKER, J.M., FORSYTH, M.H. Feather-degrading bacteria do not affect feathers on captive birds. The Auk 123:222-230, 2005.

DAROIT, D. J. Potencial queratinolítico e caracterização de uma queratinase extracelular de Bacillus sp. P45. 158 f. Tese (Doutorado) - Curso de Biologia, Universidade Federal do Rio Grande do Sul, Porto Alegre, 2011.

DIAS et al. Plumage coloration, body condition and immunological status in Yellow-billed Cardinals (Paroaria capitata), Ethology Ecology \& Evolution, 28:4, 462-476, 2016.

DOUCET, S. M.; MENNILL, D. J.; HILL, G. E. The evolution of signal design in manakin plumage ornaments. The American Naturalist. Vol. 169, No. S1, AVIAN COLORATION AND COLOR VISIONA Special Issue Edited by Andrew T. D. Bennett and Marc Théry. 2007.

DOUCET, S. M.; MEADOWS, M. G. Iridescence: a functional perspective. J. R. Soc. Interface 6, S115-S132. 2009.

FREEBERG, T.M.; DUNBAR, R.I.; ORD, T.J. Social complexity as a proximate and ultimate factor in communicative complexity. Philos Trans R Soc Lond B Biol Sci 367:1785-180. 2012

FITCH, W.T.,2010. The Evolution of Language. Cambridge: Cambridge University Press. 2010.

GALVÁN et al. Unique evolution of vitamin A as an external pigment in tropical starlings. The Company of Biologists. 2019.

GREENE et al. Disruptive sexual selection for plumage coloration in a passerine bird. Nature. 407:1000-1003. 2000

GRUNST et al. Phaeomelanin- and carotenoid-based pigmentation reflect oxidative status in two populations of the yellow warbler(Setophaga petechia). Behav Ecol Sociobiol. 68:669680. 2014.

GUNDERSON, A. R. Feather-degrading bacteria: a new frontier in avian and hosteparasite research? The Auk, 125, 972e979. 2008.

GUNDERSON et al. Resistance of melanized feathers to bacterial degradation: is it really so black and white? Journal of Avian Biology, 39, 539e545. 2008

GUNDERSON et al. Evidence that plumage bacteria influence feather coloration and body condition of eastern bluebirds Sialia sialis. Journal of Avian Biology, 40, 440e447. 2009

HART, N. S.; HUNT, D. M. Avian visual pigments:characteristics, spectral tuning, and evolution. Am. Nat. 169: S7S26. 2007.

HILL, G. E. McGRAW, K. J. Bird coloration. Vol. 1. Mechanisms and measurements. Harvard University Press, Cambridge, MA. 2006. 
HILL, G. E. Female house finches prefer colour ful males: sexual selection for a condition. Animal Behaviour 40(3):563-572. Set, 1990. 1990.

HILL, G.E. A red bird in a brown bag: the function and evolution of ornamental plumage coloration in the house finch. Oxford University Press, New York. 2002.

HILL, G.E. Proximate basis of variation in carotenoid pigmentation in male house finches. Auk. 109:1-1. 1992

HORROCKS et al. Seasonal patterns in immune indices reflect microbial loads on birds but not microbes in the wider environment. Ecosphere, 3, 19. 2012.

KINOSHITA, S.; YOSHIOKA, S.; MIYASIZAKI, J. Physics of structural colours. Rep. Prog. Phys. 71, 076401. (doi:10. 1088/0034-4885/71/7/076401). 2008.

LOZANO, G.A. Carotenoids, parasites, and sexual selection. Oikos. 70:309-311. 1994.

MAIA et al. Iridescent structural colour production in male blue-black grassquit feather barbules: the role of keratin and melanin. Journal of the Royal Society, Interface 6:203-211. 2009.

MCGRAW, K.J. The mechanics of melanin coloration in birds. In:Hill GE, Cambridge: Harvard University Press; p. 243-294. 2006

MILES, A.A.L.; MISRA, S.S. The estimation of the bacterial prower of blood. Journal of Hygiene 38, 732 \pm 749.1938.

MOLLER et al. Carotenoid-dependent signals: indicators of foraging efficiency, immunocompetence or detoxification ability? Avian and Poultry Biology Reviews, 11 (2000), pp. 137-159. 2000.

MOLLER, A. P.; POMIANKOWSKI, A. Why have birds got multiple sexual ornaments? Behavioral Ecology and Sociobiology, 32, 167e176. 1993.

MOORE et all. Queratina de penas de frango: extração caracterização e obtenção de filmes. Ciênc. Tecnol. Aliment., Campinas, 26(2): 421-427, abr.-jun. 2006.

OLSSON et al. Genetics and evolution of colour patterns in reptiles. Seminars in Cell \& Developmental Biology 24 (2013) 529-541, 2013.

ONIFADE, A.A.; AL-SANE, A.A.; AL-MUSALLA, AL-ZARBAN, S. A review: Potentials for biotechnological applications of keratin-degrading microorganisms and their enzymes for nutritional improvement of feathers and other keratins as livestock feed resources. Bioresource Technology. v. 66, p. 1-11, 1998. 
OTA, N; GAHR, M; SOMA, M. Tap dancing birds: the multimodal mutual courtship display of males and females in a socially monogamous songbird. Nature - Scientific Reports | 5:16614 | DOI: 10.1038/srep1661419 November 2015

PRADHAN, P. Colony characteristics used for identification of bacteria. Disponível em: $<$ http://microbesinfo.com/2017/07/colony-characteristics-used-for-identification-ofbacteria/>. Acesso em: 02 maio 2018.

PEREZ, I. L.; CARAZO, P.; FONT, E. Colours of quality: Structural (but not pigment) coloration informs about male quality in a polychromatic lizard. 2014.

PRYKE, S.R.; ANDERSSON, S. Carotenoid-based epaulettes reveal male competitive ability: experiments with resident and floater red-shouldered widowbirds. Animal Behaviour. 66, 217-224. 2003.

SILVA et al. Informative content of multiple plumage coloured traits in female and male European rollers. Behavioral Ecology and Sociobiology, 62, 1969 e 1979. 2008.

SHAWKEY, M.D.; HILL, G.E. Feathers at a fine scale. The Auk 141:652-655, 2004.

SHAWKEY et al. Bacteria as an agent for change in structural plumage color: correlational and experimental evidence. Am Nat 169: S112-S117. 2007.

SANGALI, S.; BRANDELLI, A. Feather keratin hydrolysis by a Vibrio sp. strain kr2. Journal of Applied Microbiology, 89, 735-743. Departamento de Ciência de Alimentos, ICTA, Universidade Federal do Rio Grande do Sul, Porto Alegre, Brasil. 2000.

SHAWKEY, M. D.; PILLAI, S. R.; HILL, G. E. Chemical warfare? Effects of uropygial oil on featherdegrading bacteria. J. Avian Biol. 34: 345/349. 2003.

SMITH, J.; HARPER, D. G. C. The evolution of aggression: can selection generate variability? Philosophical Transactions of the Royal Society of London, Series B, 319, 557e570. 1988.

STAVENGA et al. Kingfisher feathers - colouration by pigments, spongy nanostructures and thin films. J. Exp. Biol. 214, 3960-3967. 2011.

TRIGALI, A.; BOWMAN, R. Plumage reflectance signals dominance in Florida scrub-jay, Aphelocoma

coerulescens, juveniles. Animal Behaviour 84, 1517 e 1522. 2012.

TOLEDO, M.C.B.; DONATELLI, RJ.. Spectral analysis of flowers used by nectar-feeding birds in an urban area in Southeastern Brazil. Braz. J. Biol., São Carlos , v. 70, n. 3, supl. p. 729-735, 2010. 